\title{
Where next for the WHO Framework Convention on Tobacco Control?
}

\author{
Stella Bialous (i) , ${ }^{1}$ Vera Luiza Da Costa e Silva (10 ${ }^{2}$
}

${ }^{1}$ Social and Behavioral Sciences, UCSF, San Francisco, California, USA

${ }^{2}$ Center for Studies on Tobacco or Health, Oswaldo Cruz Foundation, Rio de Janeiro, Rio de Janeiro, Brazil

\section{Correspondence to}

Dr Stella Bialous, Center for Tobacco Control, UCSF, San Francisco, CA 94143, USA stella.bialous@ucsf.edu

\section{Check for updates}

(C) Author(s) (or their employer(s)) 2022. No commercial re-use. See rights and permissions. Published by BMJ.

To cite: Bialous S, Da Costa e Silva VL. Tob Control 2022:31:183-186.
At the launch of Tobacco Control in 1992, the concept of a global treaty to address the growing tobacco epidemic could have seemed farfetched but for the efforts of the late Professor Ruth Roemer who, in 1993, was encouraging tobacco control advocates to consider international treaty law to address the global needs of tobacco control. ${ }^{1}$ The rest, as it's said, is history. In 2021, the WHO Framework Convention on Tobacco Control (FCTC) completed 16 years since its entry into force and the 9th Conference of the Parties of the FCTC took place in November 2021. As we enter 2022, the treaty and the journal's history remain fundamentally connected.

As the journal's anniversary issue reflects on advances, and considers the future, of tobacco control, it offers an opportunity to look back on the FCTC's achievements and next steps. Importantly, the shared history of the journal and the treaty will continue to be linked as progress in implementing the treaty may inform a research agenda, and, conversely, cutting edge research published by the journal will inform policies that "protect present and future generations from the devastating health, social, environmental and economic consequences of tobacco consumption and exposure to tobacco smoke...". 2

\section{WHAT HAS BEEN ACHIEVED AND REMAINING CHALLENGES}

The 2021 Global Progress in Implementation of the WHO $\mathrm{FCTC}^{3}$ notes that progress in implementation of the treaty continues, if incrementally. The report observes that the most implemented articles are those focused on reducing demand for tobacco products, such as Article 8 (smokefree environments), Article 11 (warning labels on tobacco products) and Article 12 (education, communication, training and public awareness)..$^{3-5}$ Although compliance with full implementation of these three, and other, articles falls behind the minimum requirements established by the Convention for a number of Parties, ${ }^{4} 67$ there are opportunities to close these gaps in the near future. These three policies might have been perceived as "low-hanging fruit" for Parties as they benefit from available implementation guidelines and countries' experience. ${ }^{8-11}$ In addition, these policies are financially less costly to implement, and implementation depends mainly on leveraging positive public opinion and social acceptance thus preventing the tobacco industry from dominating the policy debate. Countries' experience with these policies indicates high public support and the need for minimum investments in enforcement overtime to ensure sustainability. ${ }^{891213}$

The treaty has had an overall positive impact, ${ }^{14}$ and over 4.4 billion people now live in one of the 98 countries that have implemented two or more of the treaty's tobacco demand reduction provisions. ${ }^{4}$ Although there has been an overall decline in tobacco use prevalence, quantifying the impact of the treaty on global prevalence is complex, particularly as many countries lack systematic surveillance. ${ }^{15}$ However, evidence demonstrates that strengthening the implementation of the treaty, including tobacco tax and price policies, could contribute to further prevalence decreases. ${ }^{7} 16$ Importantly, the FCTC continues to raise awareness of the multi-sectoral nature of tobacco control, has elevated the need to address the tobacco epidemic beyond ministries of health and has shed a light on the role of the tobacco industry as the principal barrier to the full implementation of the treaty. ${ }^{3} 17$

Challenges remain and include securing adequate funding for tobacco control, implementing and enforcing product regulation measures, ensuring a functional inter-governmental approach to tobacco control, and strengthening the legal system to both respond to tobacco industry challenges as well as to initiate liability claims to demand accountability from the tobacco industry for harms caused by its products. There is also a need to further international cooperation, both south-south and triangular, where countries that have successfully implemented the treaty offer technical, and practical, support on strategies to overcome political and financial barriers to strengthen tobacco control.

Another identified challenge has been the entry into several markets of electronic nicotine delivery systems (ENDS or e-cigarettes) and other nicotine products, such as nicotine pouches. While there is variation in how countries define and regulate these products (ie, whether or not these are tobacco products), ${ }^{418}$ and how countries apply the FCTC to them, the Conference of the Parties have issued policy recommendations that these products should be regulated (up to, and including, bans) in ways that protect health and prevent use by young people. ${ }^{19}$ Currently, the main market for ENDS are high-income countries, ${ }^{4}$ which allows time for lowand-middle-income countries (LMICs) to consider how to apply the precautionary principle towards regulation of these, and any novel tobacco and nicotine products. The best regulatory approach to these, and any other new products launched by the tobacco industry, will be the one that best fit each country's population needs, free from tobacco 
industry interference, while strengthening the implementation of the FCTC.

Other emerging tobacco products, such as heated tobacco products, pose less of an implementation challenge as these are clearly identified as tobacco products by the FCTC and therefore within the scope of policies recommended by the Convention. ${ }^{20-23}$ However, industry pressure ${ }^{24}$ combined with the growth of an unregulated market for novel tobacco products, and rapid emergence of new evidence, suggest that Parties might consider additional action in subsequent Conferences of the Parties. $^{25}$

\section{IS THE CONVENTION ADEQUATE TO ADDRESS MARKETS AND SOCIETY'S CHANGES?}

While the final text of the treaty, adopted in 2003 by consensus, could not possibly predict every change in markets, society and social norms, the treaty itself offers several mechanisms to ensure that it is consistent with the latest research findings and evidence-based policies to promote tobacco control and the goals of the Convention. The Convention establishes itself as floor and not a ceiling of tobacco control efforts, stating in Article 2.1 that “...Parties are encouraged to implement measures beyond those required by this Convention and its protocols, and nothing in these instruments shall prevent a Party from imposing stricter requirements...". This has resulted in the implementation, at the discretion of Parties, of policies that were not specified at the time, but that follow the intent, if not the letter, of the treaty, for example Uruguay's policy limiting cigarette brands to one single variant. ${ }^{26}$ In addition, the FCTC offers the opportunity to negotiate and adopt protocols (as Parties have done with the adoption and entry into force of the Protocol to Eliminate Illicit Trade in Tobacco Products, related to Article 15 of the Convention's text), guidelines and policy recommendations. These are practical instruments to guide Parties in the application of the treaty by incorporating additional details and addressing any new elements that were not available when the treaty was adopted. For example, Parties negotiated and adopted core Article 13 (Tobacco advertising, promotion and sponsorship)'s Guidelines in 2008. However, in 2018, Parties decided on the creation of a working group to draft a text "for specific guidelines to address cross-border TAPS [tobacco advertisement, promotion and sponsorship] and the depiction of tobacco in the entertainment media," 27 taking into account the global expansion of Internet access and smartphones, and the growth of additional entertainment and media marketing channels, including social media. These changes resulted in more ways for the tobacco industry to promote its products and influence the public and policymakers. The internet and social media expansion were not specified in the text of the Convention in 2003, nor regulated at the time, ${ }^{28}$ but the Parties' decision demonstrates the Convention's ability to address new developments.

\section{Tobacco and the environment}

There is growing evidence of the environmental harms caused by the tobacco production and supply chain. From tobacco growing to tobacco product waste, every step of the process causes environmental harms. ${ }^{29-36}$ The tobacco industry claims to be addressing such harms through voluntary measures; however, these measures will likely not be effective nor sufficient to address this growing problem. ${ }^{29}{ }^{32} 37$ An important consideration to advance the implementation of article 18 is to separate Articles 17 and 18, which have traditionally been addressed together in the development of policy options and implementation reports. ${ }^{3}$
Article 17 addresses the need to promote "viable alternative to tobacco growers" while Article 18 states that "...Parties agree to have due regard to the protection of the environment and the health of persons in relation to the environment in respect of tobacco cultivation and manufacture within their respective territories...". ${ }^{2}$ As currently reported, there is a misperception that Article 18 is applicable to less than $48 \%$ of Parties, that is, the Parties that have tobacco growing as economic activity. ${ }^{3}$ However, "protection of the environment" is not linked only to tobacco growing and Article 18 is not, therefore, applicable exclusively to tobacco-growing regions or countries but to all Parties of the FCTC. Parties could incorporate environmental harms of tobacco in educational campaigns under Article 12 (Education, communication, training and public awareness) and ban, under Article 13, the tobacco industry's environmentfocused corporate responsibility activities. In addition, Parties could determine that, for example, tobacco product waste is a by-product of tobacco manufacturing and implement measures to protect the health of the environment and of populations through product regulation that reduces or eliminates toxic waste as well as by applying liability measures to the tobacco industry. Apart from the environmental impact of conventional tobacco products, well known for trillions of non-degradable cigarette filters polluting land and oceans, novel nicotine and tobacco products contribute by adding additional plastic and e-waste to the environment. ${ }^{2938-40}$

\section{Tobacco and sustainable development}

Another example of the treaty adapting to social changes can be found in the Sustainable Development Goals (SDGs), adopted in 2015 by the United Nations. In addition to having the treaty implementation explicitly mentioned under Goal 3 , several other aspects of tobacco control support the SDGs beyond health. Through the Conference of the Parties' decisions and other documents, countries made clear that SDGs are intrinsically linked with the FCTC ${ }^{41}$ and need to reject the tobacco industry's claims that it contributes to the SDGs' implementation. ${ }^{42}$ In addition, the Convention Secretariat FCTC2030 Project, now involving 33 LMICs, continues to develop best practices on how Parties can take a whole of government approach to tobacco control, including the support for investment cases demonstrating the social and economic benefits of FCTC implementation. ${ }^{43}$ The expansion of investment cases might provide additional support to the Convention from government sectors such as finance, agriculture and trade. However, there are areas of the Convention that need to be strengthened to maximise its contribution to the SDGs and the 2030 agenda, such as designing tobacco control policies that will decrease disparities and promote equity among vulnerable groups within Parties, for example, women, indigenous populations, tobacco growers and the poor.

\section{GOING FORWARD}

The tobacco industry remains the most frequently mentioned barrier to the implementation of the FCTC, including the surge of industries producing novel tobacco and nicotine products, some of which may also produce conventional cigarettes. Still according to the 2021 Progress Report on the implementation of the FCTC, ${ }^{3}$ less than one-half of the Parties report implementing Article 5, which provides the infrastructure for a tobacco control programme and the implementation of measures associated with Article 5.3, protecting health from the tobacco industry interference. Implementation and enforcement of Article 5.3-related policies is complex, often not well understood, and existing 
reporting mechanisms of implementation may not capture ongoing tobacco industry interference with policy-making. ${ }^{174445}$ Best practices for implementation of Article 5 (including Article 5.3), especially in LMICs, must be developed to accelerate the realisation of the benefits embedded in the Articles of the FCTC.

While growing global efforts to conduct tobacco industry monitoring are underway in many countries, these efforts need to lead to policy developments that effectively create a firewall between tobacco control policy development and implementation, and the tobacco industry.

\section{The endgame}

Several Parties have initiated a discussion, or have committed, to reach an endgame from the tobacco epidemic, establishing a deadline to becoming tobacco free (or with prevalence below $5 \%$ of tobacco users) in the near future. ${ }^{46-48}$ This process will be highly impacted by market forces and what measures, if any, are implemented to curtail sales of tobacco products. It will also be influenced by public support. These measures would require a coherent systems approach, involving all sectors of the government and civil society. Further, these endgame policies need to go beyond trying to change individual behaviours and address the political and economic systems that support the tobacco industry. The FCTC could be interpreted as in support of an endgame strategy through the implementation of its provisions to the highest possible level.

Strengthening FCTC implementation could also support a move towards an endgame for countries that have yet to implement tobacco control policies (the latest WHO report stated that there are 49 countries in this group). ${ }^{4}$ With adequate financial and technical support to implement the Convention, these countries could have the opportunity to skip the several decades of incremental policy change in tobacco control and consider establishing an endgame goal in conjunction with implementation of the treaty. However, this is likely politically unfeasible. Another potential target for accelerated progress towards the endgame could be a number of countries with tobacco use prevalence below 10\%, many of which do not have any tobacco growing or manufacturing as economic interests, and which, with appropriate support from the international tobacco control community, could become the first Parties to in fact address tobacco as the harmful product that it is, and eliminate it. Based on history and experience, efforts to strengthen the implementation of the FCTC will continue to generate opposition from the tobacco industry and its allies. Such opposition needs to be adequately countered.

\section{CONCLUSION}

As with Tobacco Control, the history of the FCTC started around 30 years ago in response to the increasing death toll caused by tobacco use. While FCTC implementation is uneven, there are reasons to believe that governments made the right choice when they embraced a historic international treaty-making process. Much has changed since then, but positive results have been achieved despite continued, vigorous opposition by the tobacco industry, its allies and surrogates. The Convention is associated with mechanisms of international cooperation, an array of best practice models, and has incentivised a robust research agenda, the results of which are often found in the journal.

Furthermore, the success of the treaty created a model for public health protection that have prompted new global agendas, for example, on addressing other risk factors for non-communicable diseases. The Convention was also a pioneer when it explicitly singled out the tobacco industry as a threat to its success, and Article 5.3 is often mentioned as a model by researchers studying other commercial determinants of health. ${ }^{49-51}$

Not all contemporary challenges of the FCTC were discussed in this paper, and other aspects of the Convention must be frequently and systematically analysed. However, the Convention has served, and continues to serve, its purpose. It has the tools and the mechanisms to address current and future challenges if its implementation, in full, is continually strengthened.

Twitter Vera Luiza Da Costa e Silva @vera_dacosta

Contributors Both authors contributed, equally, to the conceptualisation, drafting and final review and approval of this manuscript.

Funding The authors have not declared a specific grant for this research from any funding agency in the public, commercial or not-for-profit sectors.

Competing interests VLDCeS was Head of the Convention Secretariat, and SB worked as a consultant for the Secretariat. VLDCeS was involved in the early days of the Tobacco Control journal launch.

Patient consent for publication Not applicable.

Ethics approval This study does not involve human participants.

Provenance and peer review Commissioned; externally peer reviewed.

ORCID iDs

Stella Bialous http://orcid.org/0000-0002-6471-5457

Vera Luiza Da Costa e Silva http://orcid.org/0000-0002-5608-7497

\section{REFERENCES}

1 The Convention Secretariat. The history of the WHO Framework Convention on Tobacco Control, 2009. Available: https://apps. who.int/iris/bitstream/handle/10665/ 44244/9789241563925_eng.pdf? sequence $=1$

2 WHO Framework Convention on Tobacco Control, 2003. Available: https://fctc. who. int/publications/i/item/9241591013

3 The Convention Secretariat. Global progress in implementation of the who FCTC. 2021. Ninth session of the conference of the parties, 2021. Available: https:// untobaccocontrol.org/downloads/cop9/main-documents/FCTC_COP_9_5_EN.pdf

4 World Health Organization. WHO Report on the Global Tobacco Epidemic 2021: addressing new and emerging products, 2021. Available: https://www.who.int/teams/ health-promotion/tobacco-control/global-tobacco-report-2021

5 Canadian Cancer Society. Cigarette package health warnings: international status report, 2021. Available: https://cdn.cancer.ca/-/media/files/about-us/media-releases/ 2021/cigarette-health-warnings-report/ccs-international-warnings-report-2021.pdf? ga $=2.40128612 .71935866 .1637262741-2107113072.1637262741$

6 Anderson CL, Mons U, Winkler V. Global progress in tobacco control: the question of policy compliance. Glob Health Action 2020;13:1844977.

7 Flor LS, Reitsma MB, Gupta V, et al. The effects of tobacco control policies on global smoking prevalence. Nat Med 2021;27:239-43.

8 Hiilamo H, Crosbie E, Glantz SA. The evolution of health warning labels on cigarette packs: the role of precedents, and tobacco industry strategies to block diffusion. Tob Control 2014;23:e2

9 Hiilamo H, Glantz SA. Implementation of effective cigarette health warning labels among low and middle income countries: state capacity, path-dependency and tobacco industry activity. Soc Sci Med 2015;124:241-5.

10 Sanders-Jackson AN, Song AV, Hiilamo H, et al. Effect of the Framework Convention on Tobacco Control and voluntary industry health warning labels on passage of mandated cigarette warning labels from 1965 to 2012: transition probability and event history analyses. Am J Public Health 2013;103:2041-7.

11 Uang R, Hiilamo H, Glantz SA. Accelerated adoption of smoke-free laws after ratification of the World Health Organization Framework Convention on Tobacco Control. Am J Public Health 2016;106:166-71.

12 Byron MJ, Cohen JE, Frattaroli S, et al. Implementing smoke-free policies in lowand middle-income countries: a brief review and research agenda. Tob Induc Dis 2019;17:60.

13 Sugden C, Phongsavan P, Gloede S, et al. Developing antitobacco mass media campaign messages in a low-resource setting: experience from the Kingdom of Tonga. Tob Control 2017:26:344-8

14 Puska P, Daube M, WHO FCTC Impact Assessment Expert Group. Impact assessment of the WHO Framework Convention on Tobacco Control: introduction, general findings and discussion. Tob Control 2019;28:s81-s83.

15 World Health Organization. WHO global report on trends in prevalence of tobacco use 2000-2025, 2021. Available: https://www.who.int/publications/i/item/who-globalreport-on-trends-in-prevalence-of-tobacco-use-2000-2025-third-edition 
16 Peruga A, López MJ, Martinez C, et al. Tobacco control policies in the 21st century: achievements and open challenges. Mol Oncol 2021;15:744-52.

17 Bialous SA. Impact of Implementation of the WHO FCTC on the tobacco industry's behavior. Tob Control 2019;28:s94-6.

18 The Convention Secretariat. Progress report on regulatory and market developments on electronic nicotine delivery systems (ENDS) and electronic non-nicotine delivery systems (ENNDS), 2018. Available: https://www.who.int/fctc/cop/sessions/cop8/FCTC COP_8_10-EN.pdf?ua $=1$

19 The Convention Secretariat. Information note on classification of novel and emerging tobacco products, 2019. Available: https://untobaccocontrol.org/impldb/wp-content/ uploads/Info-Note_Novel-Classification_EN.pdf

20 World Health Organization. Comprehensive report on research and evidence on novel and emerging tobacco products, in particular heated tobacco products, in response to paragraphs 2(a)-(d) of decision FCTC/COP8(22), 2021. Available: https:// untobaccocontrol.org/downloads/cop9/main-documents/FCTC_COP9_9_EN.pdf

21 The Convention Secretariat. Challenges posed by and classification of novel and emerging tobacco products. 2021. Ninth Session of the Conference of the Parties to the WHO FCTC, 2021. Available: https://untobaccocontrol.org/downloads/cop9/maindocuments/FCTC COP9 10 EN.pdf

22 Lempert LK, Bialous S, Glantz S. FDA's reduced exposure marketing order for IQOS: why it is not a reliable global model. Tob Control 2021. doi:10.1136/ tobaccocontrol-2020-056316. [Epub ahead of print: 02 Apr 2021].

23 Lempert LK, Glantz SA. Heated tobacco product regulation under us law and the FCTC. Tob Control 2018;27:s118-25.

24 Bialous SA, Glantz SA. Heated tobacco products: another tobacco industry global strategy to slow progress in tobacco control. Tob Control 2018;27:s111-7.

25 Conference of the Parties to the WHO Framework Convention on Tobacco Control. Provisional agenda annotated. ninth session, 2021. Available: https:// untobaccocontrol.org/downloads/cop9/main-documents/FCTC_COP_9_1_annotated_ EN.pdf

26 Crosbie E, Sosa P, Glantz SA. Defending strong tobacco packaging and labelling regulations in Uruguay: transnational tobacco control network versus Philip Morris International. Tob Control 2018;27:185-94.

27 Conference of the Parties to the WHO Framework Convention on Tobacco Control. FCTC/COP8(17) Tobacco advertising, promotion and sponsorship: depiction of tobacco in entertainment media. Decision. Available: https://fctc.who.int/publications/ $\mathrm{m} /$ item/fctc-cop8(17)-tobacco-advertising-promotion-and-sponsorship-depiction-oftobacco-in-entertainment-media [Accessed 17 Nov 2021].

28 The Convention Secretariat. First meeting of the Working group to develop specific guidelines to address Cross-border TAPS and the depiction of tobacco in the entertainment media under article 13 of the who FCTC: speech by head of convention Secretariat, 2019. Available: https://www.who.int/fctc/secretariat/head/statements/ 2019/first-meeting-of-the-working-group-cross-border-TAPS/en/

29 Hendlin YH, Bialous SA. The environmental externalities of tobacco manufacturing: a review of tobacco industry reporting. Ambio 2020;49:17-34.

30 Hopkinson NS, Arnott D, Voulvoulis N. Environmental consequences of tobacco production and consumption. Lancet 2019;394:1007-8.

31 Truth Initiative. Tobacco and the environment, 2021. Available: https://truthinitiative. org/research-resources/harmful-effects-tobacco/tobacco-and-environment [Accessed 25 Sep 2021].

32 Novotny TE, Bialous SA, Burt L, et al. The environmental and health impacts of tobacco agriculture, cigarette manufacture and consumption. Bull World Health Organ 2015;93:877-80.
33 Novotny TE, Lum K, Smith E, et al. Cigarettes butts and the case for an environmental policy on hazardous cigarette waste. Int J Environ Res Public Health 2009;6:1691-705.

34 Tobacco Free CA. Cigarette butts are toxic waste, 2021. Available: https:// tobaccofreeca.com/environment/cigarette-butts-are-toxic-waste/ [Accessed $25 \mathrm{Sep}$ 2021].

35 Zafeiridou M, Hopkinson NS, Voulvoulis N. Cigarette smoking: an assessment of tobacco's global environmental footprint across its entire supply chain. Environ Sci Technol 2018;52:8087-94.

36 Zafeiridou M, Hopkinson NS, Voulvoulis N. Technical report for the FCTC: cigarette smoking, an assessment of tobacco's global environmental footprint across its entire supply chain and policy strategies to reduce it, 2018. Available: http://www.who.int/ fctc/publications/WHO-FCTC-Enviroment-Cigarette-smoking.pdf?ua=1

37 McDaniel PA, Malone RE. British American Tobacco's partnership with Earthwatch Europe and its implications for public health. Glob Public Health 2012;7:14-28.

38 Chang H. Research gaps related to the environmental impacts of electronic cigarettes. Tob Control 2014:23:ii54-8.

39 Mock J, Hendlin YH. Notes from the Field: Environmental Contamination from E-cigarette, Cigarette, Cigar, and Cannabis Products at 12 High Schools - San Francisco Bay Area, 2018-2019. MMWR Morb Mortal Wkly Rep 2019;68:897-9.

40 Truth Initiative. A toxic, plastic problem: e-cigarette waste and the environment, 2021. Available: https://truthinitiative.org/research-resources/harmful-effects-tobacco/toxicplastic-problem-e-cigarette-waste-and-environment

41 The Convention Secretariat. Guide for who FCTC parties on including SDG target 3.a in voluntary national reviews, 2020. Available: https://www.who.int/fctc/VNR_Guide_ 7July2020.pdf

42 Stopping Tobacco Organizations and Products (STOP). How tobacco industry interference hinders the UN Sustainable Development Goals, 2020. Available: https:// exposetobacco.org/wp-content/uploads/TI-hinders-SDGs.pdf

43 The Convention Secretariat. FCTC2030, 2021. Available: https://fctc. who.int/who-fctc/ development-assistance/fctc-2030 [Accessed 10 Oct 2021].

44 Smith $\mathrm{KE}$, Gilmore $A B$, Fooks $\mathrm{G}$, et al. Tobacco industry attempts to undermine Article 5.3 and the "good governance" trap. Tob Control 2009;18:509-11.

45 Hawkins B, Holden C. European Union implementation of Article 5.3 of the framework convention on tobacco control. Global Health 2018;14:79.

46 Damiani A, Peseckyte G. EU wants tobacco-free generation as smoking numbers rise worldwide. Euractiv. Available: https://www.euractiv.com/section/health-consumers/ news/eu-wants-tobacco-free-generation-as-smoking-numbers-rise-worldwide/ [Accessed 10 Oct 2021].

47 Timberlake DS, Laitinen U, Kinnunen JM, et al. Strategies and barriers to achieving the goal of Finland's tobacco endgame. Tob Control 2020;29:398-404.

48 Rea E. New Zealand government proposes world-leading action plan to achieve Smokefree 2025 goal. BMJ 2021 https://blogs.bmj.com/tc/2021/05/05/new-zealandgovernment-proposes-world-leading-action-plan-to-achieve-smokefree-2025-goal/

49 Mialon M, Vandevijvere S, Carriedo-Lutzenkirchen A, et al. Mechanisms for addressing and managing the influence of corporations on public health policy, research and practice: a scoping review. BMJ Open 2020;10:e034082.

50 Collin J. Taking steps toward coherent global governance of alcohol: the challenge and opportunity of managing conflict of interest. J Stud Alcohol Drugs 2021:82:387-94.

51 Ralston R, Hil SE, da Silva Gomes F, et al. Towards preventing and managing conflict of interest in nutrition policy? An analysis of submissions to a consultation on a draft WHO tool. Int J Health Policy Manag 2021;10:255-65. 